\title{
Prospective study of maternal perception of decreased fetal movement in third trimester and evaluation of its correlation with perinatal compromise
}

\author{
Nupur Nandi, Ritika Agarwal*
}

\begin{abstract}
Department of Obstetrics and Gynecology, Teerthankar Mahaveer Medical College and Research Center, Moradabad, Uttar Pradesh, India
\end{abstract}

Received: 14 November 2018

Accepted: 29 December 2018

\author{
*Correspondence: \\ Dr. Ritika Agarwal, \\ E-mail: drritika2@yahoo.com
}

Copyright: () the author(s), publisher and licensee Medip Academy. This is an open-access article distributed under the terms of the Creative Commons Attribution Non-Commercial License, which permits unrestricted non-commercial use, distribution, and reproduction in any medium, provided the original work is properly cited.

\begin{abstract}
Background: Intrauterine fetal movements are sign of fetal life and well being. Perception of decreased fetal movements by the expecting mother is a common concern for both the mother and her obstetrician. Inadequate evaluation of reported decreased fetal movements may lead to catastrophic perinatal outcome. These necessitates us to identify the mothers perceiving decreased fetal movements, evaluating them to identify any risk factor, and follow up them to know the correlation with perinatal outcome.

Methods: Antenatal mothers with singleton pregnancy at third trimester are recruited from OPD/ Emergency of Obstetrics and Gynaecology departments of Teerthankar Mahaveer Medical College and Research Center, Moradabad, Uttar Pradesh, India. Both case and control group comprise of 80 mothers matched by demographic profile, with perception of decreased fetal movements only in case group. They were evaluated thoroughly to identify risk factor if any and were followed up till delivery to know the perinatal outcome.

Results: Majority of women reporting reduced fetal movements were between 20-30 years of age group (73\%), Primigravida (80\%), $72.5 \%$ were at term pregnancy. Common $(46 \%)$ pattern of decreased movements was both in frequency and as well as intensity. $62 \%$ women with decreased fetal movements had anteriorly placed placenta. In the study group, $48.75 \%$ women were identified with risk factor, and association of more than one antenatal risk factor was significantly high ( $\mathrm{p}$ value 0.0026 ). LBW was more common (21.25\%), many neonates were associated with low Apgar score in the study group.

Conclusions: Pregnant mothers reported with decreased fetal movement in third trimester should be evaluated adequately for identification of risk factors, as well as for fetal surveillance. Record of fetal movement for 2 hours while the mother is in rest, Cardiotocography, elaborative USG, BPP should be monitored to have good perinatal outcome by providing timely intervention.
\end{abstract}

Keywords: Apgar score, BPP, Decreased fetal movement, LBW

\section{INTRODUCTION}

Fetal movements are considered as a sign of fetal life and well-being. ${ }^{1}$ Maternal perceptions of fetal movements are the result of pressure against abdominal wall due to gross fetal movement or limb movement. ${ }^{2}$ Monitoring fetal movements is a useful tool to assess fetal well-being. ${ }^{1}$
Prevalence of decreased fetal movement perceptionin third trimester has been reported as $4-15 \%$ in various studies. ${ }^{1,3,4}$ Association between maternal perception of decreased fetal movement and poor perinatal outcome like fetal growth restriction, oligohyramnios, fetal distress, preterm births, fetal congenital anomalies, and stillbirth are revealed in different studies. ${ }^{5-7}$ Besides fetal 
factor, perception of fetal movements can be affected by position of placenta (common in anterior), administration of corticosteroids in antenatal period, cigarette smoking, alcohol intake, use of sedative drugs, increased maternal blood sugar, even maternal position, activity. ${ }^{8-13}$

It is also found that inadequate measures taken by the obstetrician to the complaints of decreased fetal movements is a contributor to stillbirth. ${ }^{14}$ In this perspective, decreased perception of fetal movement by the mother in the third trimester of pregnancy concerned her obstetrician.

In their study, Sergent et al showed that women who report decreased fetal movement are to be assessed for additional fetal surveillance tests. These can vary from simple repeat counting of fetal movements to hospital admissionof mother during which repeated cardiotocography (CTG), bio-physical profile (BPP), Doppler studies, Kleihauer-Betke's test, and even amnioscopy are performed. ${ }^{4}$

In this background, we planned present study to assess the significance of decreased fetal movement perception in third trimester of pregnancy with the perinatal outcome. We admitted all those mothers reporting reduced fetal movement and monitored themtill delivery by repeat fetal movement counts, CTG, USG, BPP, Umbilical artery (UA)Doppler study. Mothers were investigated for identification of antenatal risk factors. Modes of delivery, Apgar score of neonate at birth, birth weight, NICU admission were noted.

The objectives of the present study were to identify the mothers complaining of decreased fetal movements and to investigate them for the fetal well-being, to identify the antenatal risk factors related to decreased fetal movements, to evaluate perinatal outcome of those pregnancies reported with decreased fetal movements.

\section{METHODS}

Authors had done this study at Obstetrics and Gynaecology Department of Teerthankar Mahaveer Medical College, Moradabad from August 2017 till August 2018 after getting desired permission from the ethical committee of the said institution.

Study population: Antenatal mothers from OPD/ Emergency in their third trimester of pregnancy were selected by checking inclusion and exclusion criteria. After getting written consent for the study by the subjects, our sample size was 80 pregnant women reporting with perception of reduced fetal movements between 29 th to 40 weeks of gestation.

80 pregnant women with no complaints of decreased fetal movements matched for age, parity of the study population and delivery within 48 hours of admission served as our control group.

\section{Inclusion criteria}

- Antenatal mothers with known date of 1st day of last menstrual period with a history of at least three regular cycles prior to conception.

- Singleton live pregnancy of 29th to 40th week's gestation with perception of decreased fetal movements.

- Matched menstrual age of fetus with that of documented first trimester USG.

\section{Exclusion criteria}

- Diagnosed IUFD, gross congenital malformation, multi-fetal pregnancy, history of antepartum haemorrhage, preconception irregular menstrual cycle, gestational age beyond the said period.

\section{Study tools}

CTG machine (BPL), USG machine (Voluson).

\section{Design}

Tt was a prospective observational study with random recruitment of subjects for case and control group by using inclusion and exclusion criteria.

A detailed history was recorded including antenatal risk factors (like GDM, HTN, Obstetric cholestasis, Anaemia, history of smoking, alcohol, sedative intake), time since onset of decreased fetal movements, pattern of less movement (frequency/intensity, or both). General physical and obstetrical examinations were performed. Women reporting decreased fetal movements were asked to keep an account of fetal movement for next 2 hours while resting in left lateral decubitus. CTG was performed within 2 hours at least for 20 minutes and result was interpreted according to NICE guidelines. ${ }^{15}$ Women showing pathological or suspicious CTG was delivered immediately. Others were investigated for complete hemogram, OGTT, LFT, TSH and routine urine evaluation. A detail USG with Doppler study follows to record AFI, placental location and grading, exact fetal maturity and EFW, BPP (Manning score), umbilical artery $\mathrm{S} / \mathrm{D}$ ratio. If all the parameters were within satisfactory limits and maternal record of fetal movements for 2 hours showed at least 10 fetal movements, mothers were discharged and follow up were done during delivery.

Mode of delivery and neonatal outcome regarding birth weight, Apgar scoring, NICU admission necessities were taken into account.

\section{RESULTS}

Demographic profile of mothers and period of gestation (POG) at the time of reporting decreased fetal movements in both the groups is summarized in Table 1. 
Table 1: Maternal demographic profiles, POG (case and control).

\begin{tabular}{|c|c|c|c|c|}
\hline \multirow[t]{2}{*}{ Characteristics } & \multicolumn{2}{|c|}{ Study group } & \multicolumn{2}{|c|}{ Control group } \\
\hline & $\begin{array}{l}\text { Number } \\
\mathbf{n}=\mathbf{8 0}\end{array}$ & $\%$ & $\begin{array}{l}\text { Number } \\
\mathbf{n}=\mathbf{8 0}\end{array}$ & $\%$ \\
\hline \multicolumn{5}{|l|}{ Age } \\
\hline$<20$ years & 10 & 12 & 7 & 9 \\
\hline 20-30 years & 58 & 73 & 65 & 81 \\
\hline$>30$ years & 12 & 15 & 8 & 10 \\
\hline \multicolumn{5}{|l|}{ Gravida } \\
\hline Primi & 64 & 80 & 52 & 65 \\
\hline Multi & 16 & 20 & 28 & 35 \\
\hline \multicolumn{5}{|l|}{ Residence } \\
\hline Semiurban/rural & 53 & 66 & 68 & 85 \\
\hline Urbaan & 27 & 34 & 12 & 15 \\
\hline \multicolumn{5}{|l|}{ Education } \\
\hline 8-10 standard & 41 & 51 & 51 & 64 \\
\hline$>10^{\text {th }}$ standard & 39 & 49 & 29 & 36 \\
\hline \multicolumn{5}{|l|}{ Per capita income } \\
\hline$<8000$ & 25 & 31 & 31 & 39 \\
\hline$>8000$ & 55 & 69 & 49 & 61 \\
\hline \multicolumn{5}{|l|}{ POG at reporting } \\
\hline $37-40$ weeks & 58 & 72.5 & 53 & 66 \\
\hline$<37$ weeks & 22 & 27.5 & 27 & 34 \\
\hline
\end{tabular}

Values expressed in number and percentage. $\mathrm{P}$ values were not significant, so we didn't mention meaning both the groups were matched sufficiently. Pattern of decreased fetal movements in study population are represented in table 2. Most of the women (46\%) reported of perceiving fewer movements, as well as decrease in intensity of movements.
Table 2: Distribution of mothers as per pattern of perception of decreased fetal movements.

\begin{tabular}{|l|l|l|}
\hline Pattern & $\mathbf{N}=80$ & $\%$ \\
\hline Frequency & 33 & 41 \\
\hline Intensity & 10 & 13 \\
\hline Both & 37 & 46 \\
\hline
\end{tabular}

Authors investigated both the group of mothers for identification of any risk factor like GDM, hypothyroidism, anaemia, obesity, hypertension, and cholestasis of pregnancy.

Thirty-nine $(48.75 \%)$ women from study group had at least one antenatal risk factor, in compare to 27 women from control group (33.75\%). Fifteen women from the study group $(18.75 \%)$ had multiple antenatal risk factors, whereas in control group only $3(3.75 \%)$ mothers had multiple risk factors which is statistically significant ( $p$ value 0.0026 )

USG revealed, majority of women (49) perceiving less fetal movements had anteriorly placed placenta (62\%) with significant p-value of $<0.001$ when compared with control group.

Sixty-seven women in the study group had normal BPP (score of 8 or more). From these women thirty hadone or more antenatal risk factor, thirteen $(19.40 \%)$ women had delivered a low birth weight (LBW) baby, six neonates $(8.9 \% \%)$ require NICU admission. It signifies, no single test can identify all compromised fetuses (Table 3 ).

Table 3: Distribution of cases with normal BPP and perinatal outcome.

\begin{tabular}{|c|c|c|c|c|}
\hline $\begin{array}{l}\text { No. of cases with } \\
\text { normal BPP (n) }\end{array}$ & $\begin{array}{l}\text { Antenatal risk factors } \\
\text { present (n) }\end{array}$ & Mean birth weight (kg) & LBW (n) (\%) & $\begin{array}{l}\text { NICU admission (n) } \\
(\%)\end{array}$ \\
\hline 67 & 30 & $2.72 \pm 0.50$ & $13(19.40)$ & $6(8.9 \%)$ \\
\hline
\end{tabular}

In the total study group ( $\mathrm{n}=80)$, two $(2.5 \%)$ women had abnormal umbilical artery Doppler, and both of them delivered a LBW baby.

Out of 78 subjects with normal UA Doppler $(<3$ S/D ratio), 15 babies were LBW. In the study group total 7 neonates born with APGAR $<=6$ of which one baby was fresh stillborn in a GDM mother with poor BPP. AFI (cm) score of study group showed $7(8.75 \%)$ had oligohydramnios $(\mathrm{AFI}<5)$, of these three women $(42.85 \%, \mathrm{n}=7)$ delivered LBW baby.

In the study group sixteen $(20 \%)$ mother were delivered by emergency $C$ section. Out of them $(n=16)$, nine
(56.25\%) had antenatal risk factor, seven (43.75\%) had low BPP score.

Table 4: Distribution of participants (case and control) with Apgar score at one minute and delivering neonates with $\mathrm{LBW}$.

\begin{tabular}{|l|l|l|}
\hline $\begin{array}{l}\text { Criteria } \\
\text { Apgar score }\end{array}$ & $\begin{array}{l}\text { Case (\%) } \\
\mathbf{N}=80\end{array}$ & $\begin{array}{l}\text { Control (\%) } \\
\text { N=80 }\end{array}$ \\
\hline $\begin{array}{l}\leq 6 \\
>6\end{array}$ & $7(8.75)$ & $3(3.75)$ \\
\hline $\begin{array}{l}\text { LBW (birth } \\
\text { weight }<2.5 \mathrm{~kg})\end{array}$ & $73(91.25)$ & $77(96.25)$ \\
\hline
\end{tabular}




\section{DISCUSSION}

Study conducted from August 2017 till August 2018 with 80 pregnant women recruited following inclusion and exclusion criteria with perception of decreased fetal movement. Control group was selected from mothers with no complaints of less fetal movement matched for demographic profile, other criteria and delivered within 48 hours of admission.

Majority (80\%) of the subjects in the study group were primigravida as compared to control group (65\%). A cohort study by RCOG shows $50.2 \%$ women with reduced fetal movement were primi $(n=138)$ in comparison to $37 \%(\mathrm{n}=98)$ in control group. ${ }^{15}$ First perception of fetal movements occur from 18 to 22 weeks of gestation which increases up to 32 weeks thereafter it plateaus till the onset of labour. $72.5 \%$ cases of decreased fetal movement presentation were at term. In present study $46 \%$ women reported for decreased frequency as well as intensity of fetal movements. Saastad E et al recommended that the reduction in frequency of fetal movement in late third trimester to be considered alarming for fetal outcome. ${ }^{14}$

It has been reported that pregnant women with anteriorly placed placenta commonly present with less fetal movements, which is supported in present study $(62 \%)$ with significant $\mathrm{p}$-value of $<0.001$ in comparison to control group. Thirty-nine women $(48.75 \%)$ of study group had at least one antenatal risk factor in compare to $33.75 \%$ (27) women from control group. But this finding was not statistically significant, may be due to small sample size. However, 15 women $(18.75 \%)$ of study group had more than one risk factor. In control group only 3 women $(3.75 \%)$ had more than one risk factor with a highly significant $p$ value (0.0026) when comparison is done. Froen JF stated in a South Australian clinical guideline on decreased fetal movement that various antenatal risk factors are associated with this condition and obstetrician should find out those factors. ${ }^{3}$ Tveit JV et al showed in a prospective cohort study of 305 women with decreased fetal movement 67 had poor perinatal outcome. ${ }^{16}$ Of these 67 , four were identified by CTG, 20 by USG assessment of fetal growth.

In present study, 13 women from 80 cases were found to have BPP of less than 6 of whom 4 had LBW, 9 had antenatal complications, one had oligohydramnios $(\mathrm{AFI}<5)$, one baby delivered as stillborn. But all of them had normal CTG on admission that means women with reported less fetal movement should be assessed by various tools to identify compromised fetuses. False negative rate of BPP in high risk pregnancy has been shown to be $0.07 \%$ suggesting that fetal death is rare in women with normal BPP. ${ }^{17,18}$ In the lone case of stillborn in present study, the woman had GDM, the neonate was LBW. Six out of all (13) LBW babies from normal BPP had oligohydramnios, therefore measurement of AFI is supposed to be beneficial for fetal surveillance. When combined with maternal characteristics, prediction models improved with significant AUC ( $\mathrm{p}<0.0001$ ): 0.643 for EFWG and 0.640 for CAH, CAI and EFWH. With the addition of maternal characteristics, the detection rate at $10 \%$ false positive rate increased from $13.3 \%$ to $20.6 \%, 13.3 \%$ to $20.6 \%, 12.4 \%$ to $22.8 \%$ and $11.0 \%$ to $20.6 \%$ for $\mathrm{ACH}$, EFWH, EFWG and ACI, respectively. ${ }^{19}$

Study done in 2017 in India found a very significant proportion with abnormal BPP (39\%) among high risk group and corresponding proportion among low risk group being only $9 \%$. Thus, RFM should be taken very seriously among high risk group and they need timely delivery to prevent stillbirth. ${ }^{20}$

\section{CONCLUSION}

Pregnant mothers reporting with decreased fetal movement perception in third trimester should be evaluated by detailed history taking, thorough investigation to identify risk factors, as well as for fetal well-being. After admitting all such cases, record of fetal movement for 2 hours while the mother is in rest, Cardiotocography, elaborative USG including UA Doppler study, BPP should be monitored to have good perinatal outcome by providing timely intervention.

\section{Funding: No funding sources}

Conflict of interest: None declared

Ethical approval: The study was approved by the Institutional Ethics Committee

\section{REFERENCES}

1. Rayburn WF. Fetal body movement monitoring. ObstetGynecol Clin North Am. 1990;17(1):95-110.

2. Tuffnell DJ, Cartmill RS, Lilford RJ. Fetal movements; factors affecting their perception. Europe J Obstet Gynaecol Reproduct Biol. 1991;39(3):165-7.

3. Froen JF. A kick from within- fetal movement counting and the cancelled progress in antenatal care. J Perinat Med. 2004;32(1):13-24.

4. Sergent F, Lefevre A, Verspyck E, Marpeau L. Decreased fetal movements in the third trimester: what to do? Gynecologie Obstetrique et Fertilite. 2005;33(11):861-9.

5. Grant A, Elbourne D, Valentin L, Alexander S. Routine formal fetal movement counting and risk of antepartum late death in normally formed singletons. Lancet. 1989;2(8650):345-9.

6. Harrington K, Thompson O, Jordan L, Page J, Carpenter G, Campbell S. Obstetric outcome in women who present with a reduction in fetal movements in the third trimester of pregnancy. J Perinat Med. 1998;26(2):77-82.

7. O' Sullivan O, Stephen G, Martindale EA, Heazell AE. Predicting poor perinatal outcome in women who present with decreased fetal movements- a 
preliminary study. J Obstet Gynecol. 2009; 29(8):705-10.

8. Neldam S, Jessen P. Fetal movements registered by the pregnant woman correlated to retrospective estimations of fetal movements from cardiotocographic tracings. Am J Obstet Gynecol. 1998;136(8):1051-4.

9. Mulder EJ, Derks JB, Visser GH. Antenatal corticosteroid therapy and fetal behavior: a randomized study of the effects of betamethasone and dexamethasone. Br. J Obstet Gynaecol.1997; 104(11):1233-8.

10. Manning F, Wyn Pugh E, Boddy K. Effect of cigarette smoking on fetal breathing movements in normal pregnancies. Br. Med. J 1975;1(5957): 552-3.

11. Castillo RA, Devoe LD, Ruedrich DA, Gardner P. The effects of acute alcohol intoxication on biophysical activities: a case report. Am J Obstet Gynecol. 1989;160(3):692-3.

12. Robertson SS, Dierker LJ. Fetal cyclic motor activity in diabetic pregnancies: sensitivity to maternal blood glucose. Dev Psychobiol. 2003;42(1):9-16.

13. Cito G, Luisi S, Mezzesimi A, Cavicchioli C, Calonaci G, Petraglia F. Maternal position during non-stress test and fetal heart rate patterns. Acta Obstet Gynecol Scand. 2005,84(4):335-8.

14. Saastad E, Vangen S, Froen JF. Suboptimal care in stillbirths- a retrospective audit study. Acta Obstet Gynecol Scand. 2007;86(4):444-50.

15. National Collaborating Centre for Women's and Children's Health. Intrapartum care. Care of healthy women and their babies during childbirth. RCOG press; 2007.

16. Tveit JV, Saastad E, Stray Pedersen B, Bordhal PE, Flenady V, Fretts R et al. Reduction of late stillbirth with the introduction of fetal movement information and guidelines- a clinical quality improvement. BMC Preg Childbirth. 2009;9(1):32.

17. Manning FA, Morrison I, Harman CR, Lange IR, Menticoglou S. Fetal assessment based on fetal biophysical profile scoring: experience in 19,221 reffered high risk pregnancies. An analysis of falsenegative fetal deaths. Am J Obstet Gynecol. 1987; 157(4):880-4.

18. Dayal AK, Manning FA, Bereck DJ, Mussalli GM, Avila C, Harman CR et al. Fetal death after normal biophysical profile score: An eighteen-year experience. Am J Obstet Gynecol 1999; 181(5):1231-6.

19. Reboul Q, Delabaere A, Wu Y, Nuyt A, Fraser W, Luo $\mathrm{Z}$ et al. OC02.02: Prediction of perinatal outcomes by third trimester fetal biometry and maternal characteristics. Ultras Obstet Gynecol. 2015;46(S1):3

20. Poojari V, Kumar S, Vasudeva A. Obstetric and neonatal outcome among women presenting with reduced fetal movements in third trimester. Int $\mathbf{J}$ Reprod Contracept Obstet Gynecol. 2017;7(1):88-93.

Cite this article as: Nandi N, Agarwal R. Prospective study of maternal perception of decreased fetal movement in third trimester and evaluation of its correlation with perinatal compromise. Int J Reprod Contracept Obstet Gynecol 2019;8:687-91. 